\title{
Influência das Variáveis Térmicas Sobre os Espaçamentos Dendríticos Terciários durante a Solidificação Direcional Horizontal da Liga Al-6\%Cu
}

\author{
José Marcelino Dias Filho ${ }^{1}$, Rafael Hideo Kikuchi ${ }^{2}$, \\ Thiago Antônio Paixão de Sousa Costa ${ }^{2}$, Antonio Luciano Seabra Moreira ${ }^{2}$, \\ Otávio Fernandes Lima da Rocha ${ }^{1}$
}

\author{
${ }^{1}$ Instituto Federal de Educação, Ciência e Tecnologia do Pará - IFPA, Av. Almirante Barroso 1155 \\ CEP: 66093-020, Belém, Pará, Brasil. \\ e-mail: marcelino_dias@hotmail.com; rafaelkikuchi@hotmail.com; otvrocha@oi.com.br \\ ${ }^{2}$ Universidade Federal do Pará-UFPA, Programa de Pós-Graduação em Eng. Mecânica - PPGEM \\ Av. Augusto Corrêa 1, CEP: 66075-110, Belém, Pará, Brasil. \\ e-mail: tcosta88@gmail.com; 1moreira@amazonet.com.br
}

\section{RESUMO}

A liga $\mathrm{Al}-6 \% \mathrm{Cu}$ foi solidificada direcionalmente sob condições transitórias de extração de calor e microestruturas dendríticas, variáveis térmicas de solidificação, ou seja, velocidade de deslocamento da isoterma líquidus $\left(\mathrm{V}_{\mathrm{L}}\right)$, taxa de resfriamento $\left(\mathrm{T}_{\mathrm{R}}\right)$ e gradiente de temperatura à frente da isoterma liquidus $\left(\mathrm{G}_{\mathrm{L}}\right)$ foram caracterizadas, determinadas experimentalmente e correlacionadas com os espaçamentos dentríticos terciários $\left(\lambda_{3}\right)$. Para tanto, foi projetado, construído e aferido um dispositivo de solidificação direcional horizontal. Os resultados encontrados mostram que leis de potência $-1,1$ e $-0,55$ caracterizam a variação dos espaçamentos terciários com a velocidade de deslocamento da isoterma liquidus $\left(\mathrm{V}_{\mathrm{L}}\right)$ e a taxa de resfriamento $\left(\mathrm{T}_{\mathrm{R}}\right)$, respectivamente. Finalmente, é realizado um estudo comparativo entre os resultados obtidos neste trabalho e aqueles publicados na literatura para ligas Al-Cu solidificadas direcionalmente sob condições transientes de fluxo de calor nos sistemas verticais ascendente e descendente.

Palavras-chave: solidificação direcional horizontal, espaçamento dendrítico terciário, ligas Al-Cu.

\begin{abstract}
The Al-6wt $\% \mathrm{Cu}$ alloy was directionally solidified and dendritic microstructure, solidification thermal variables, i.e., tip growth rate $\left(\mathrm{V}_{\mathrm{L}}\right)$, cooling rate $\left(\mathrm{T}_{\mathrm{R}}\right)$ and temperature gradient ahead of liquidus isotherm $\left(\mathrm{G}_{\mathrm{L}}\right)$ were characterized and correlated with tertiary dendritic spacings $\left(\left(\lambda_{3}\right)\right.$ determined experimentally. For this purpose, a horizontal solidification experimental apparatus was developed and specimens were solidified under unsteady state heat flow conditions. It was observed that power laws -1.1 and -0.55 characterize the tertiary spacing variations with tip growth rate $\left(\mathrm{V}_{\mathrm{L}}\right)$ and cooling rate $\left(\mathrm{T}_{\mathrm{R}}\right)$, respectively. Comparisons with other studies published in the literature for $\mathrm{Al}-\mathrm{Cu}$ alloys solidified in upward and downward vertical directional conditions were performed.
\end{abstract}

Keywords: horizontal directional solidification, tertiary dendritic spacing, Al-Cu alloys.

\section{INTRODUÇÃO}

Com as crescentes exigências da indústria moderna por materiais com propriedades cada vez mais elevadas o conhecimento e, por conseguinte, o controle da cinética do processo de solidificação de metais e ligas metálicas vem a cada dia se consolidando como um objeto de estudo de extrema importância para a obtenção de materiais com propriedades homogêneas e cada vez mais adequadas à sua utilização prática. Deste modo, é essencial a abordagem de algumas metodologias utilizadas no estudo do referido fenômeno destacando-se, por exemplo, a técnica da solidificação direcional a qual pode ser aplicada tanto em condições estacionárias quanto em regime transiente de extração de calor. Vale destacar, que a maioria dos resultados experimentais 
envolvendo aspectos macro e microestruturais resultantes do processo de solidificação presentes na literatura [1], utilizam condições estacionárias de troca de calor, entretanto, a maioria dos processos industriais ocorre em condições transitórias de fluxo de calor. Assim, importantes estudos [2-12], têm sido realizados nas últimas décadas com o objetivo de ser estabelecida de forma sistematizada a influência dos diversos parâmetros térmicos e operacionais envolvidos no fenômeno da solidificação sobre a estrutura resultante, buscando elevar as propriedades mecânicas e, por conseguinte, o desempenho dos materiais solidificados por meio do desenvolvimento de métodos matemáticos de caráter analítico ou numérico e de procedimentos experimentais na grande maioria implementados em sistemas de solidificação direcionais verticais ascendentes $[\underline{3}-10,14-17]$ e descendentes $[11,18,19]$. No que se refere ao sistema com configuração horizontal, são raros os trabalhos na literatura $[\underline{20}, \underline{21}]$ que abordam $\mathrm{o}$ assunto.

Quando realizado na forma vertical ascendente, em condições de gradiente de temperatura positivo no líquido, o efeito da convecção é minimizado quando o soluto é direcionado para regiões interdendríticas, promovendo um líquido mais denso que o volume global do metal líquido e uma solidificação mais estável termicamente. No caso da solidificação vertical descendente o fenômeno da convecção no líquido, devido o soluto rejeitado e o efeito da gravidade, são preponderantes na formação da morfologia da microestrutura frente à interface sólido/liquido pois, ao contrário da solidificação vertical ascendente, pode ocorrer o fenômeno da convecção termossolutal, isto é, convecção devido ao movimento de soluto frente a esta interface. Por outro lado, na solidificação direcional horizontal, quando o fluxo de calor é extraído através de somente uma das paredes laterais do molde, a convecção em função dos gradientes de composição no líquido, a convecção termossolutal e o efeito da gravidade, estão presentes. Portanto, uma interessante característica adicional do sistema horizontal é o gradiente de concentração de soluto bem como os efeitos de densidade na direção vertical uma vez que o líquido enriquecido de soluto sempre decanta ao passo que o solvente tende a emergir devido as forças de flutuabilidade. Além disso, devido os efeitos impostos pela convecção termossolutal, sempre vai ocorrer um gradiente de temperaturas na direção vertical. A Figura 1 apresenta esquematicamente os modos de transferência de calor que podem ocorrer ao longo da solidificação direcional horizontal em um molde refrigerado a água, ou seja, convecção forçada na água, transferência newtoniana na interface água/molde, condução no molde, transferência newtoniana na interface metal/molde, condução térmica no metal sólido, convecção natural e condução térmica no metal líquido.

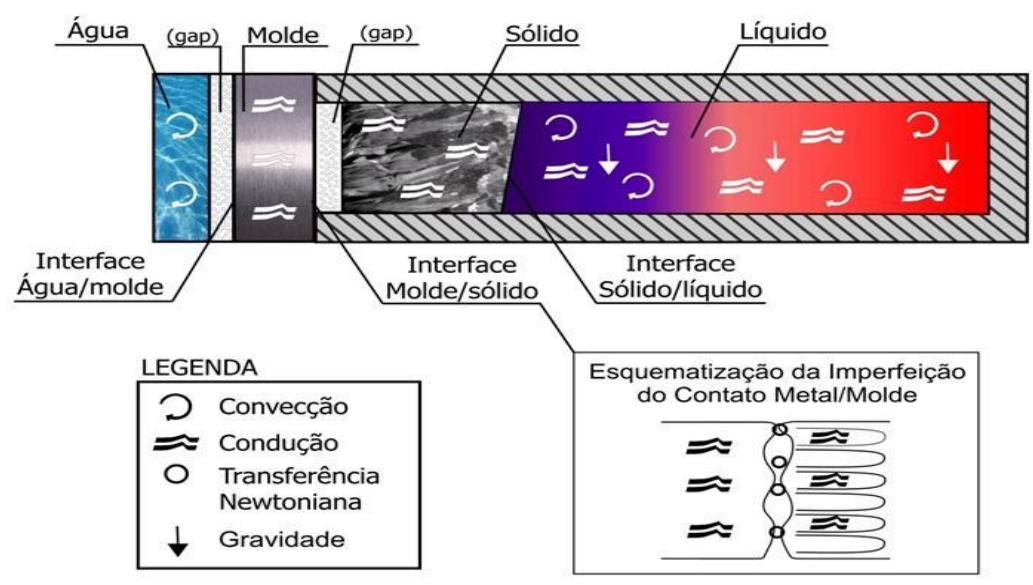

Figura 1: Modos de transferência de calor atuantes no sistema metal/molde na solidificação horizontal [1].

As microestruturas resultantes do processo de solidificação, estão relacionadas com a forma da interface sólido/líquido. Em condições ideais essa interface deveria permanecer plana, contudo, alterações nos parâmetros constitucionais e térmicos do sistema metal/molde que ocorrem durante a solidificação provocam a instabilidade da mesma, originando microestruturas celulares e dendríticas. Durante a mudança de fase, a rejeição de soluto ocorrida à frente da fronteira sólido/líquido origina um fenômeno que favorece a nucleação conhecido na literatura como superresfriamento constitucional [1] que influenciará diretamente a morfologia da interface sólido/líquido. A Figura 2 mostra, de forma esquemática, o efeito da concentração de 
soluto $\left(\mathrm{C}_{0}\right)$, velocidade de deslocamento da isoterma liquidus $\left(\mathrm{V}_{\mathrm{L}}\right)$ e gradiente térmico $\left(\mathrm{G}_{\mathrm{L}}\right)$ na instabilidade da interface sólido/líquido e, consequentemente, na formação das microestruturas.

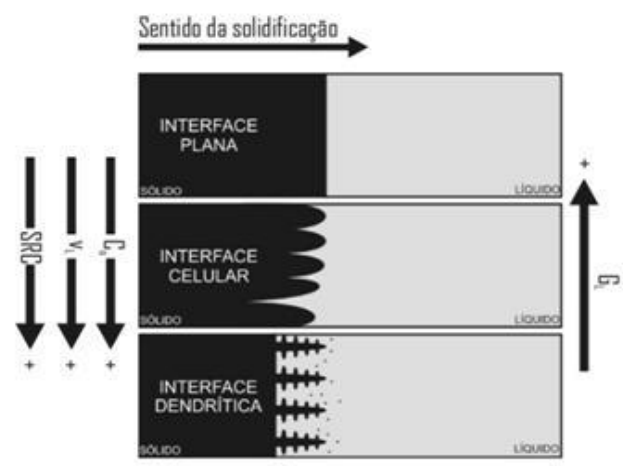

Figura 2: Representação esquemática da atuação dos fatores de influência na formação das microestruturas de solidificação [1].

A continuidade do aumento do grau de superresfriamento constitucional induz instabilidades de maior ordem com surgimento de braços secundários e, a partir destes, os terciários que caracterizam as redes dendríticas, conforme apresentado na Figura 3. As distâncias entre centros de células e de ramificações ou braços dendríticos são definidas como espaçamentos intercelulares e interdendríticos, que são muito utilizados para caracterizar quantitativamente a microestrutura formada.

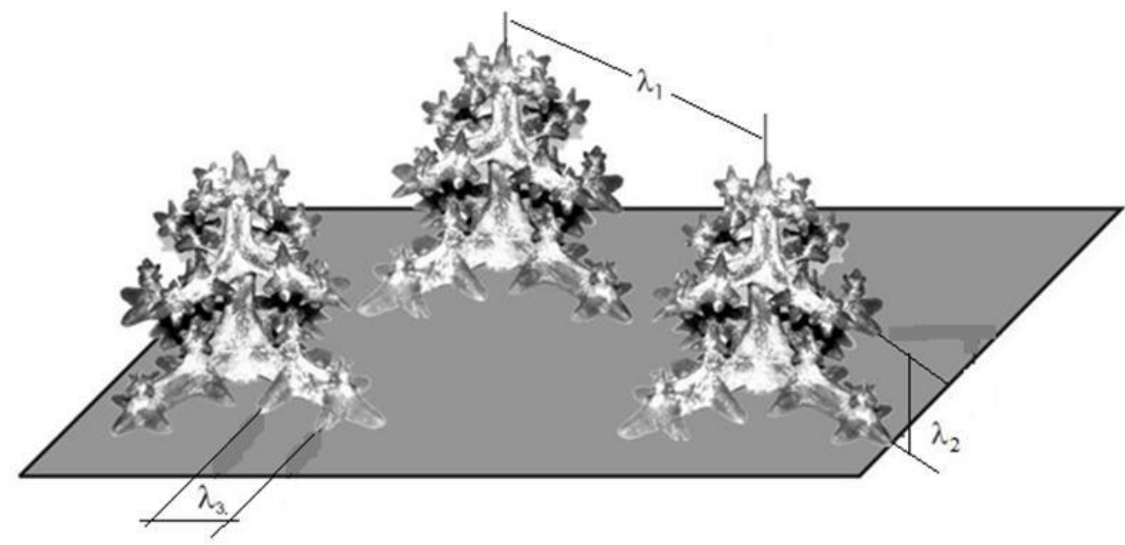

Figura 3: Esquema representativo das ramificações interdendríticas primárias $(\lambda 1)$, secundárias $(\lambda 2)$ e terciárias $(\lambda 3)$ [19].

Como observado na Figura 3, os espaçamentos dendríticos terciários fazem parte integrante da estrutura dendrítica. Esses espaçamentos também exercem influência sobre as propriedades dos materiais fundidos e quando se encontram presentes na estrutura a literatura recomenda que as propriedades tenham que ser relacionadas com o espaçamento de maior grau, no caso em questão o terciário [1]. Atualmente na literatura não existem modelos teóricos assim como são quase inexistentes estudos experimentais que visam a quantificação dos espaçamentos dendríticos terciários $\left(\lambda_{3}\right)$ em função das variáveis térmicas de solidificação para solidificação transitória de extração de calor. Os que existem, são todos elaborados para o caso da solidificação vertical.

Gurgel [22], utilizando um sistema de solidificação Bridgman, determinou uma lei experimental de variação de $\lambda_{3}$ em função do tempo local de solidificação para ligas hipoeutéticas Al-Si, dada por:

$$
\lambda_{3}=10\left(\mathrm{t}_{\mathrm{SL}}\right)^{1 / 3}
$$

Mais recentemente, Sá et al [14] utilizando um sistema de solidificação direcional vertical ascendente obtiveram para ligas hipoeutéticas dos sistemas $\mathrm{Sn}-\mathrm{Pb}$ e $\mathrm{Al}-\mathrm{Cu}$ relações experimentais para $\lambda_{3}$ em função de 
$V_{L}$ e $T_{R}$ sob condições transitórias de extração de calor. Os resultados encontrados permitiram a determinação de uma correlação entre a composição química e esses parâmetros térmicos capaz de indicar condições de solidificação para o surgimento das ramificações terciárias. Rosa et al [19] propuseram leis experimentais de crescimento para $\lambda_{3}$ em função de $T_{R}$ para ligas hipoeutéticas Al-Si solidificadas sob regime transiente de extração de calor em dois sistemas de solidificação direcional vertical, sendo um ascendente e outro descendente. Posteriormente, Moutinho [16] e Gomes [17], ambos utilizando sistemas de solidificação direcional vertical ascendente, apresentaram pela primeira vez expressões de $\lambda_{3}$ em função de $V_{L}$ e $T_{R}$ para ligas multicomponentes (Al-Cu-Si). Moutinho [16] comparou seus resultados experimentais de $\lambda_{3}$ com aqueles obtidos por Boeira [23] para a liga binária $\mathrm{Al}-6,2 \% \mathrm{Cu}$ mostrando que as referidas ligas ternárias apresentam uma única lei experimental de evolução de $\lambda_{3}$ com taxa de resfriamento, dada pela equação experimental $\lambda_{3}=41,2\left(\mathrm{~T}_{\mathrm{R}}\right)^{-0,55}$, que é muito próxima daquela obtida por Boeira [23] para a liga Al-6,2\% Cu. De maneira geral, as leis experimentais encontradas na literatura $[14,16,17,19,23]$ para solidificação direcional vertical transitória que coorrelecionam $\lambda_{3} \operatorname{com} V_{L}$ e $T_{R}$ são expressas pelas seguintes equações:

$$
\begin{aligned}
& \lambda_{3}=\mathrm{A}_{1}\left(\mathrm{~V}_{\mathrm{L}}\right)^{-1,1} \\
& \lambda_{3}=\mathrm{A}_{2}\left(\mathrm{~T}_{\mathrm{R}}\right)^{-0,55}
\end{aligned}
$$

onde, segundo os referidos autores, A e B dependem do teor de soluto.

Considerando a elevada importância do assunto, destacando que inexistem na literatura estudos sobre crescimento dendrítico terciário relacionados à solidificação direcional horizontal, os principais objetivos deste trabalho são: (a) determinar as variáveis térmicas de solidificação $\mathrm{V}_{\mathrm{L}}$ e $\mathrm{T}_{\mathrm{R}}$ para a liga Al$6 \% \mathrm{Cu}$ solidificada direcionalmente em um dispositivo com configuração horizontal sob regime transiente de extração de calor; (b) caracterizar e quantificar a microestrutura bruta de fusão obtida permitindo correlacionar $\lambda_{3}$ com as respectivas variáveis térmicas por meio de relações experimentais e (c) comparar os resultados encontrados com os previstos na literatura para o caso da solidificação direcional vertical ascendente e descendente.

\section{MATERIAIS E MÉTODOS}

A liga investigada foi obtida a partir de lingotes de alumínio e cobre comercialmente puros, cujas composições químicas são apresentadas na Tabela 1. Para elaboração da mesma, os referidos lingotes foram seccionados em pequenas quantidades em uma serra de fita na proporção estequiometricamente exata e a seguir pesados em uma balança eletrônica analítica com precisão de $0,01 \mathrm{~g}$. $\mathrm{O}$ alumínio foi introduzido em um cadinho de carbeto de silício, previamente revestido com uma camada de alumina para evitar a contaminação das ligas, sendo em seguida conduzido até um forno tipo mufla, com temperatura máxima de trabalho de $1250{ }^{\circ} \mathrm{C}$, interiormente revestido com placas refratárias e controle de processamento de temperatura. Devido as temperaturas de fusão dos componentes da liga estudada serem bastante diferentes, a mesma foi obtida mediante o mecanismo de difusão do soluto na matriz líquida do solvente, ou seja, após a total fusão do alumínio o cadinho foi retirado do forno sendo então o cobre adicionado ao metal líquido. A mistura foi homogeneizada com uma vareta de aço revestida com alumina a fim de facilitar a incorporação do cobre na matriz de alumínio.

Tabela 1: Análise química dos metais utilizados para preparação da liga $\mathrm{Al}-6 \% \mathrm{Cu}$.

\begin{tabular}{c|c|c|c|c|c|c|c|c|c|c|c}
\hline \multirow{2}{*}{ Metal } & \multicolumn{10}{c}{ Composição Química (\%) } \\
\cline { 2 - 13 } & $\mathrm{Al}$ & $\mathrm{Fe}$ & $\mathrm{Ni}$ & $\mathrm{Cu}$ & $\mathrm{Si}$ & $\mathrm{Mg}$ & $\mathrm{Pb}$ & $\mathrm{Cr}$ & $\mathrm{Mn}$ & $\mathrm{Zn}$ & $\mathrm{Sn}$ \\
\hline $\mathrm{Al}$ & 99.68 & 0.175 & 0.0148 & 0.0242 & 0.103 & 0.0011 & - & - & - & - & - \\
\hline $\mathrm{Cu}$ & - & - & - & 99.64 & 0.09 & - & 0.002 & 0.27 & - & - & - \\
\hline
\end{tabular}

Após a difusão do soluto na matriz do solvente, a mistura metálica foi retornada ao forno mufla tendo em seguida sido retirada novamente para ser homogeneizada e caracterizada termicamente para a obtenção da respectiva curva de resfriamento a fim de serem confirmadas as temperaturas liquidus $\left(\mathrm{T}_{\mathrm{L}}\right)$ e solidus $\left(\mathrm{T}_{\mathrm{S}}\right)$, correspondentes ao início e final da solidificação, conforme indicado no diagrama de equilíbrio de fases, para 
ajuste da composição de soluto. A Figura 4 apresenta o diagrama de equilíbrio de fases parcial do sistema Al$\mathrm{Cu}$ e a respectiva curva de resfriamento experimental obtida para a liga $\mathrm{Al}-6 \% \mathrm{Cu}$.

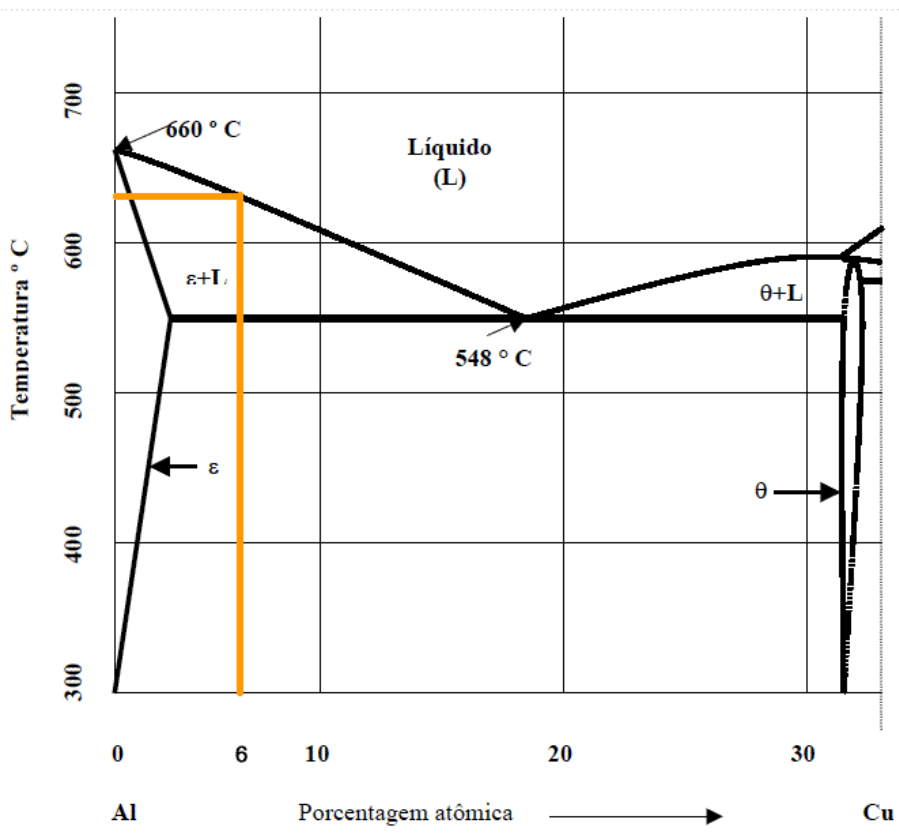

(a)

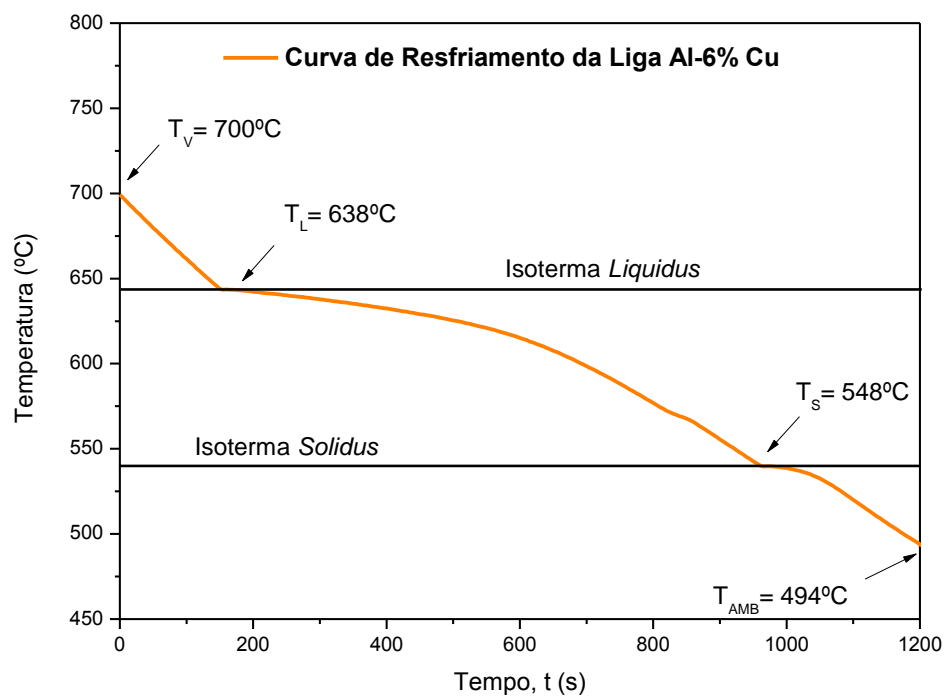

(b)

Figura 4: (a) Diagrama de equilíbrio parcial do sistema $\mathrm{Al}-\mathrm{Cu}$ [7]; (b) Curva experimental de resfriamento obtida para a liga $\mathrm{Al}-6 \% \mathrm{Cu}$.

O dispositivo de solidificação e o sistema de aquisição de dados empregados nos experimentos são mostrados de forma esquemática nas Figuras 5 e 6. Utilizado pela primeira vez por Silva [20], foi projetado de tal maneira que o calor do metal líquido fosse extraído somente através de um sistema refrigerado a água, localizado em uma das paredes laterais do molde, promovendo assim a solidificação direcional horizontal. A lingoteira de aço inoxidável utilizada possui $110 \mathrm{~mm}$ de comprimento, $70 \mathrm{~mm}$ de largura, $60 \mathrm{~mm}$ de altura e $3 \mathrm{~mm}$ de espessura. As superfícies laterais internas da mesma foram revestidas com camadas de alumina e a parte superior foi isolada com material refratário para evitar perdas de calor para o meio ambiente. A condição de contato térmico na interface metal/molde foi padronizada com a superfície de extração de calor sendo polida. Alguns experimentos foram inicialmente realizados com o objetivo de aferir-se a direcionalidade do fluxo de calor por parte do dispositivo de solidificação. 
Inicialmente, a liga estudada foi fundida in situ no dispositivo de solidificação e, em seguida, levada até a temperatura correspondente a $10 \%$ acima de sua temperatura liquidus, visando garantir a formação da zona colunar uma vez que os espaçamentos terciários devem ser quantificados na referida região [1]. Após atingido o nível de superaquecimento desejado, as resistências elétricas do dispositivo foram então desligadas e imediatamente acionado o sistema de refrigeração a água. Os jatos do fluido refrigerante, direcionados tão somente a uma das paredes laterais do molde, induziram uma extração de calor no sentido longitudinal, ou seja, apenas na direção horizontal conforme estabelecido neste estudo. Os valores das temperaturas no metal fundido foram medidos em diferentes posições durante a solidificação e os dados obtidos foram armazenados automaticamente. Para tanto, cinco termopares tipo K (Chromel - Alumel) foram posicionados, conforme indicado nas Figuras 5 e 6, a distâncias correspondentes a 5, 10, 15, 30 e $50 \mathrm{~mm}$ da superfície de extração de calor. Os termopares foram calibrados com base no ponto de fusão do alumínio indicando flutuações em torno de $1^{\circ} \mathrm{C}$ e conectados através de cabos coaxiais a um sistema de aquisição de dados em um computador. As principais características dos termopares utilizados são as seguintes: diâmetro igual a 1,5 mm; faixa de utilização até $1260^{\circ} \mathrm{C}\left(0,000\right.$ a 50,990) $\mathrm{mV}$; potência termoelétrica: 4,04 mV $\left(100{ }^{\circ} \mathrm{C}\right)$. O AMR-Software, marca ALMEMO Data-Control, foi o software utilizado para acompanhar, registrar e armazenar os dados obtidos pelos termopares durante o processo de solidificação, além de possibilitar um monitoramento on-line dos dados medidos.

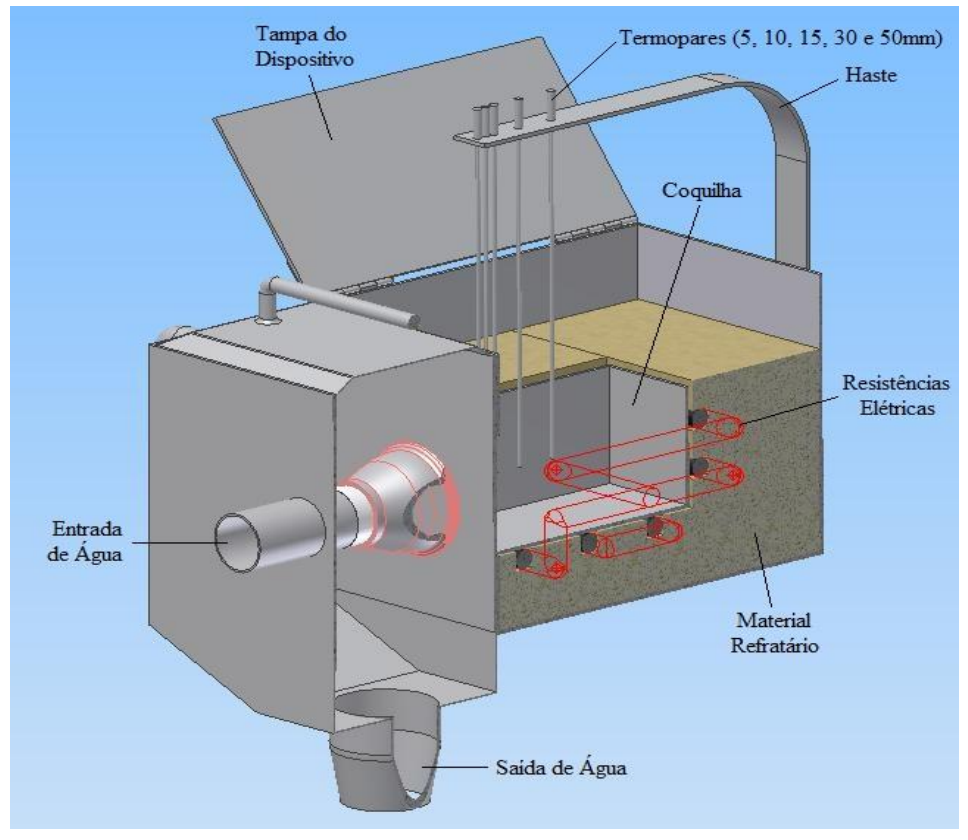

Figura 5: Representação esquemática do dispositivo de solidificação direcional horizontal utilizado nos experimentos deste trabalho [20]. 


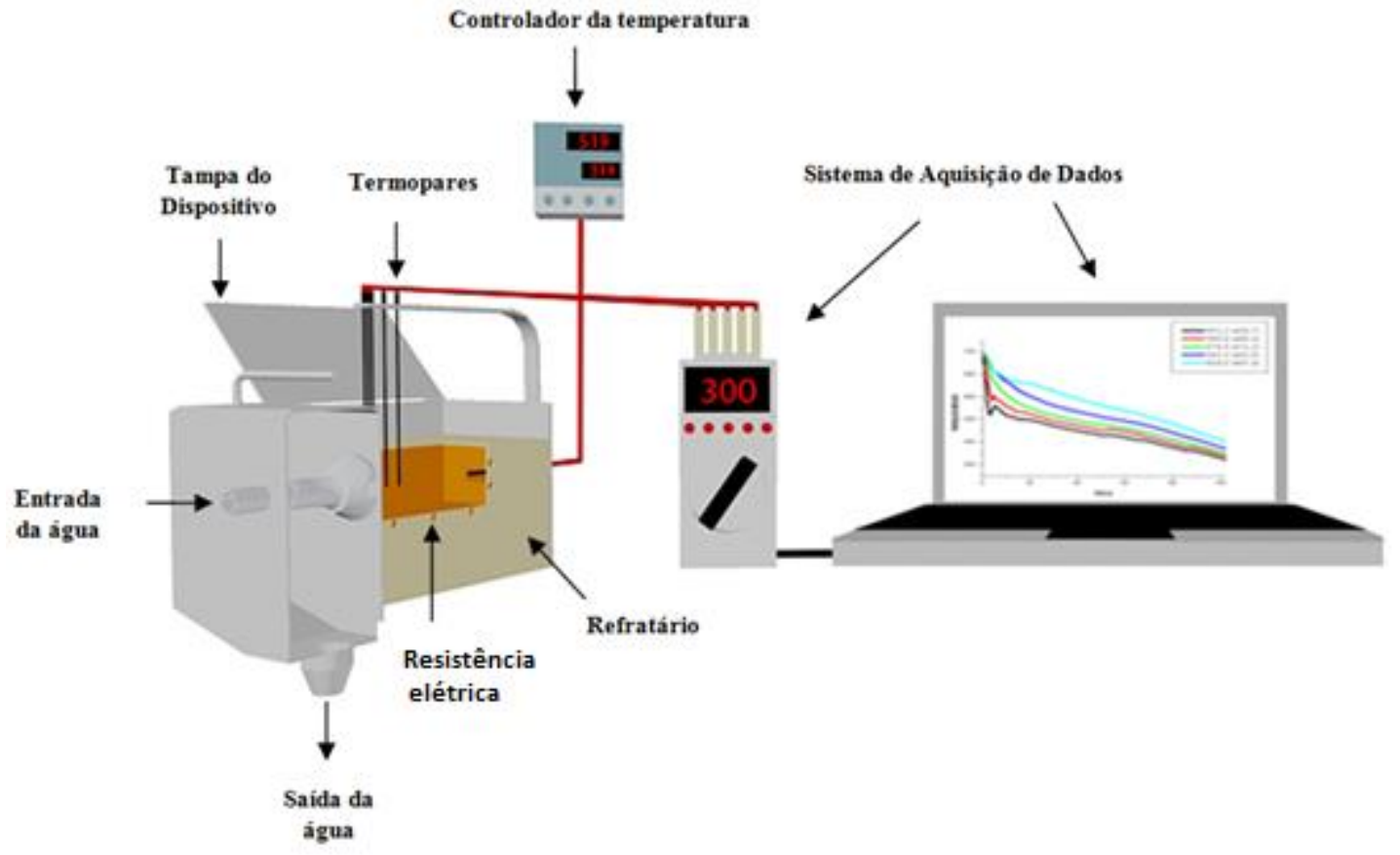

Figura 6: Representação esquemática do dispositivo de solidificação mostrando sua interface com o sistema de registro a de temperaturas [20].

Finalmente, para caracterizar e quantificar a estrutura dendrítica analisada, inicialmente foi revelada macroestrutura de solidificação visando avaliar-se a direcionalidade da extração de calor e, ao mesmo tempo, identificar o limite de formação dos grãos colunares pois a literatura $[\underline{14}, \underline{16}, \underline{17}, \underline{23}]$ orienta que é na região de crescimento desses grãos que os espaçamentos terciários devem ser medidos. Após essa etapa, foram retirados transversalmente ao longo do comprimento longitudinal do lingote seis corpos de prova, nas posições correspondentes a 10,15, 20, 30, 40 e $50 \mathrm{~mm}$ em relação à interface metal/molde, destacando que na posição de $50 \mathrm{~mm}$ foi observada a transição colunar/equiaxial (TCE). Em seguida, os corpos de prova foram embutidos a frio, lixados e polidos com pasta de diamante de $6 \mu \mathrm{m}$ até $1 \mu \mathrm{m}$. Finalmente, foi realizado o ataque químico com solução de $5 \%$ de $\mathrm{NaOH}$ em água destilada para revelar as microestruturas. As medidas de $\lambda_{3}$ foram realizadas utilizando-se o software Image Tool (IT), disponível na internet. O método para quantificar os valores desses espaçamentos foi utilizado por Sá et al. [14], Rosa et al. [19] e McCartney e Hunt [24]. O mesmo baseia-se no cálculo do valor de $\lambda_{3}$ pela média das distâncias entre os braços adjacentes ao longo do comprimento " $n$ " sobre a seção transversal do lingote, aproximadamente no mesmo sentido da ramificação dendrítica primária. O espaçamento terciário expressa a razão entre essa dimensão total e o número de distâncias centro a centro percorridas (n). A Figura 7 representa, esquematicamente, a metodologia em questão. 


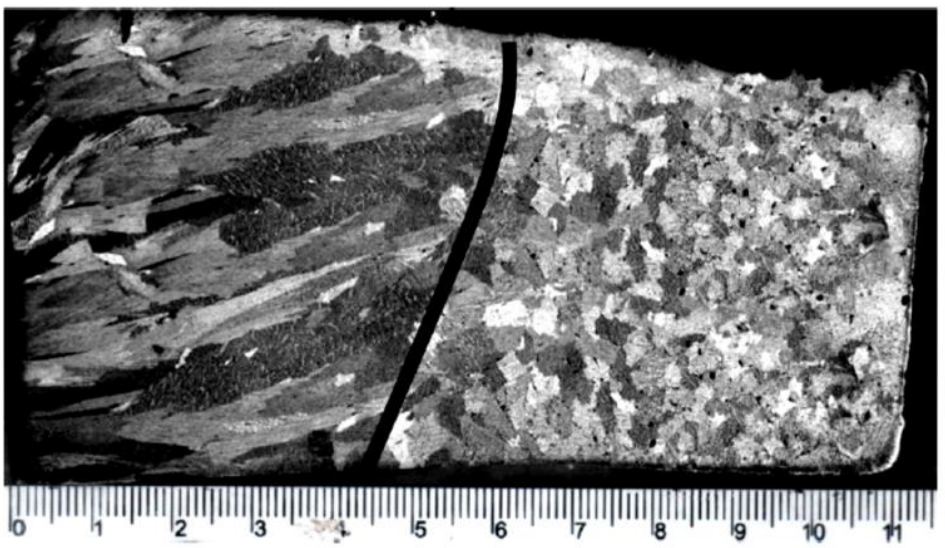

(a)
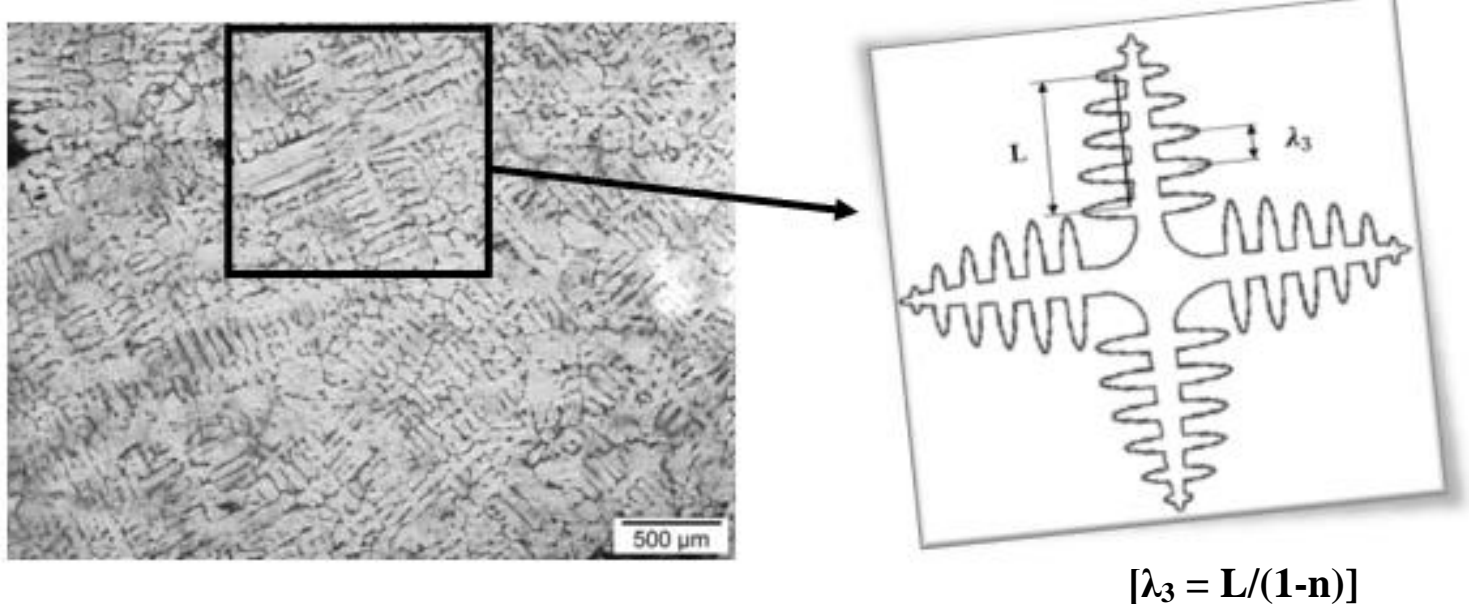

(b)

Figura 7: (a) Macrografia da liga Al-6\%Cu mostrando a TCE; (b) Micrografia apresentando a estrutura dendrítica e o método da medição dos espaçamentos terciários.

\section{RESULTADOS E DISCUSSÕES}

\subsection{Variáveis Térmicas de Solidificação $\left(V_{L}, T_{R}\right.$ e $\left.G_{L}\right)$}

A Figura 8 mostra os perfis térmicos experimentais de solidificação para os cinco termopares localizados no metal, a partir da superfície de extração de calor. Esses perfis foram utilizados para calcular a posição da isoterma liquidus em função do tempo. A função $\mathrm{P}=\mathrm{f}(\mathrm{t})$ foi definida experimentalmente pela interseção da reta equivalente à temperatura liquidus $\left(\mathrm{T}_{\mathrm{L}}\right)$ da liga com o perfil térmico correspondente à posição de cada termopar, isto é, a partir da $\mathrm{T}_{\mathrm{L}}$ da liga é traçada uma reta paralela ao eixo do tempo, indicado no gráfico que representa os perfis térmicos. Por meio da interseção da reta proveniente da $T_{L}$ com o perfil térmico de cada termopar, determina-se o tempo correspondente à posição do referido termopar que pode ser definido como sendo o tempo de passagem da isoterma liquidus naquela posição. Os resultados dos pares ordenados $(\mathrm{P}, \mathrm{t})$ obtidos a partir do procedimento em questão possibilita que seja plotado um gráfico experimental da posição da isoterma liquidus com o tempo, conforme mostrado na Figura 9. 


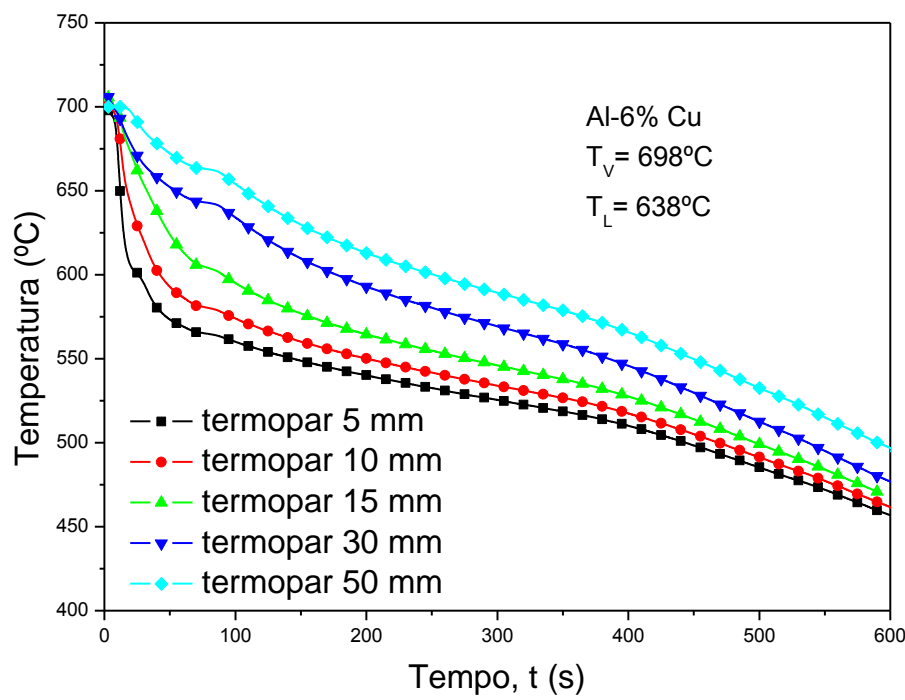

Figura 8: Curvas experimentais de resfriamento. $\mathrm{T}_{\mathrm{V}}$ é a temperatura de vazamento.

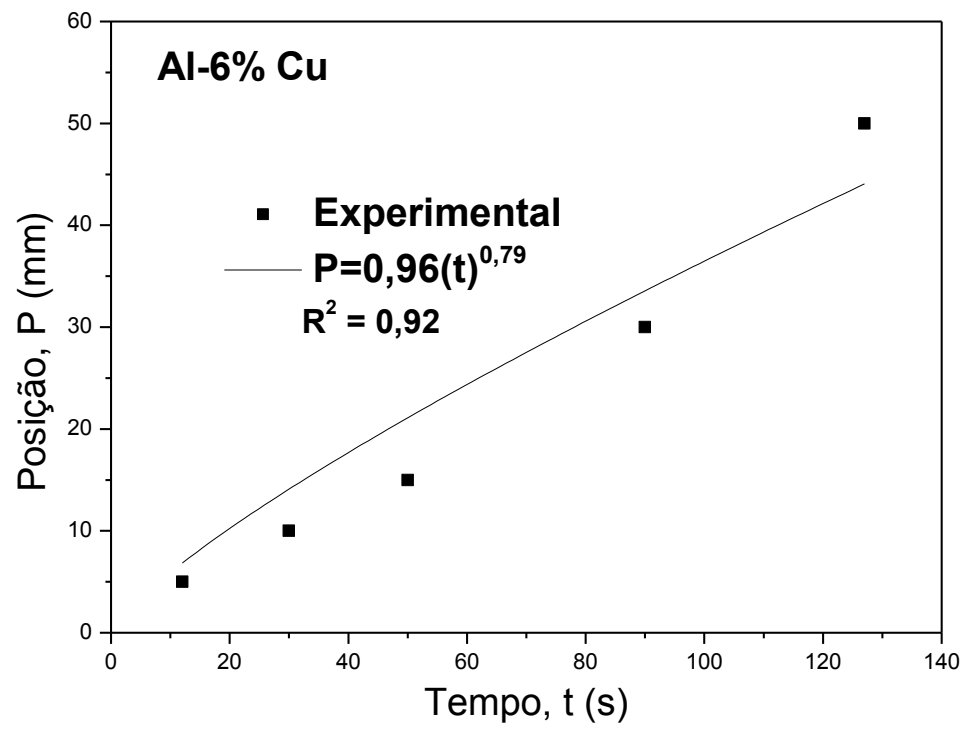

Figura 9: Posição da isoterma liquidus a partir da interface metal/molde em função do tempo.

A derivada da função potência da posição com relação ao tempo, ou seja, dP/dt, permitiu a obtenção dos respectivos valores experimentais para as velocidades de deslocamento da isoterma liquidus $\left(\mathrm{V}_{\mathrm{L}}\right)$ a partir da interface metal/molde em função do tempo, o que corresponde à passagem da frente líquida por cada termopar. Os resultados obtidos são apresentados na Figura 10 na qual se observa a diminuição progressiva da velocidade com o avanço da solidificação. Por outro lado, os valores das taxas de resfriamento $\left(T_{R}\right)$ foram determinados considerando também os perfis experimentais de temperatura (Figura 8), conforme metodologia apresentada anteriormente por um dos autores deste trabalho [7,8], ou seja, a taxa de resfriamento para cada posição dos termopares foi obtida experimentalmente a partir das interseções da reta da temperatura liquidus com os perfis térmicos equivalentes a cada posição dos termopares, através do resultado da leitura direta do quociente das temperaturas imediatamente antes e depois da temperatura liquidus e dos tempos correspondentes, isto é, $T_{R}=\Delta T / \Delta t$. Assim, com base nos pontos experimentais foram geradas funções potência da taxa de resfriamento em função da posição cujos resultados encontram-se indicados na Figura 11. 


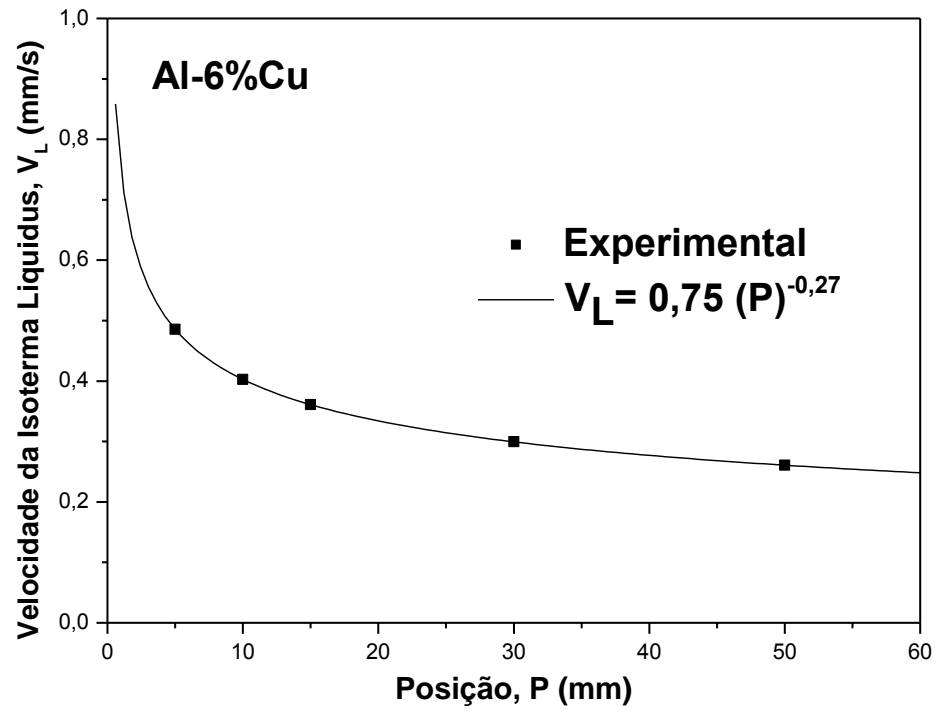

Figura 10: Velocidades de deslocamento da isoterma liquidus em função da posição a partir da interfacemetal/molde.

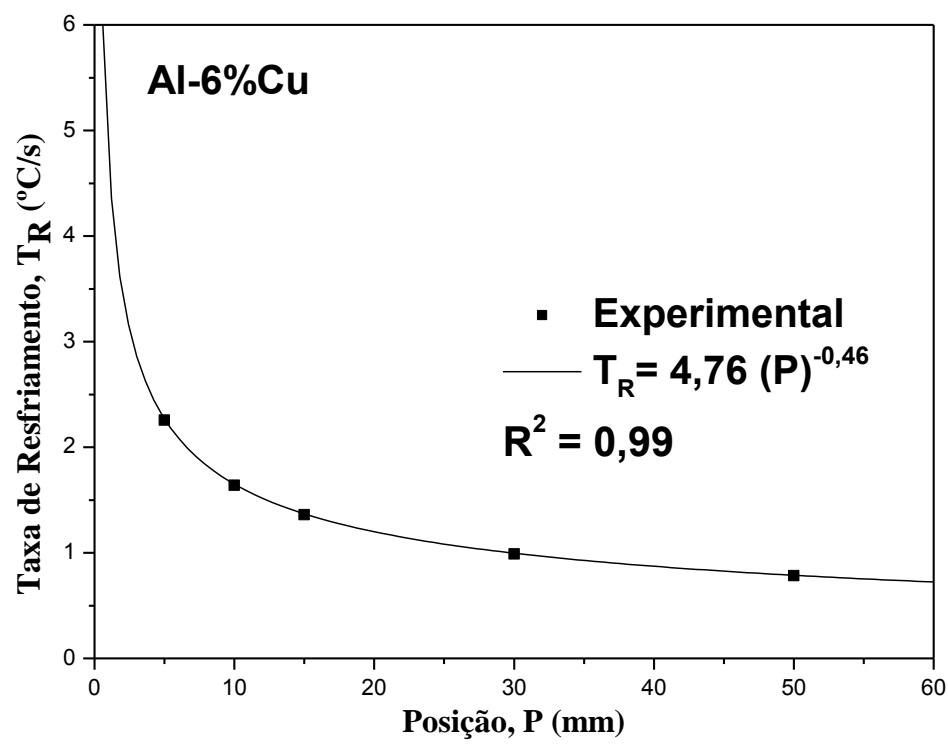

Figura 11: Taxas de resfriamento em função da posição a partir da interface metal/molde.

Finalmente, os gradientes térmicos frente à isoterma liquidus $\left(\mathrm{G}_{\mathrm{L}}\right)$ referentes à liga estudada foram determinados através da relação analítica entre as respectivas taxas de resfriamento e as velocidades de deslocamento da isoterma liquidus, ou seja, $T_{R}=G_{L} V_{L}[1]$. Os valores encontrados estão indicados na Figura 12.

Da mesma forma que o observado para o caso do comportamento da velocidade de deslocamento da isoterma liquidus, a taxa de resfriamento e o gradiente de temperatura diminuem com o avanço da solidificação, isto é, quanto mais afastados da base refrigerada menores são os valores de $V_{L}, T_{R}$ e $G_{L}$. Tal fato pode ser explicado pela elevação da resistência térmica à extração de calor por condução ao longo do processo de solidificação, devido ao aumento da camada solidificada. 


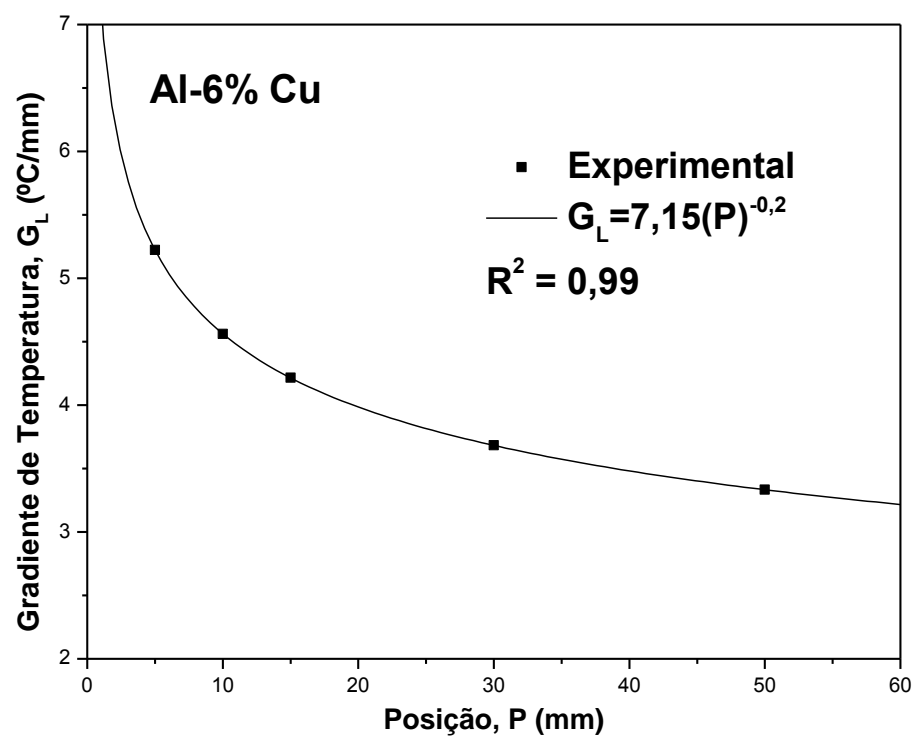

Figura 12: Gradientes de temperatura em função da posição a partir da interface metal/molde.

As Figuras 14, 15 e 16 apresentam os resultados experimentais das medições dos espaçamentos dendríticos terciários à medida que a solidificação evolui. As linhas equivalem às equações experimentais obtidas e representam, respectivamente, as leis de crescimento desses espaçamentos com a posição, velocidade e taxa de resfriamento. Observa-se, em todos os casos, um excelente coeficiente de correlação $\left(\mathrm{R}^{2}\right.$ $>0,7)$ entre os pontos e as curvas correspondentes. Conforme citado anteriormente, para a caracterização e quantificação da estrutura dendrítica terciária, em cada posição foram analisadas microestruturas distantes 5, 10, 15, 20, 30, 40 e $50 \mathrm{~mm}$ (ocorrência da TCE) da chapa molde, entretanto, somente foi possível verificar e quantificar os referidos espaçamentos a partir da posição $10 \mathrm{~mm}$, indicando um ponto (Figura 13) em que os ramos dendríticos terciários surgem a partir dos ramos secundários. Além da posição da isoterma liquidus, estes espaçamentos foram parametrizados em função de $V_{L}$ e $T_{R}$, conforme mostram as Figuras 14 e 15 .

Observa-se que os expoentes -1,1 e -0,55 caracterizam as leis experimentais de $\lambda_{3}$ em função de $V_{L}$ e $\mathrm{T}_{\mathrm{R}}$, respectivamente. Tais expoentes são os mesmos encontrados por Sá [14] para ligas Al-Cu, Moutinho [16] e Gomes [17] para as ligas ternárias $\mathrm{Al}-6 \% \mathrm{Cu}-1 \% \mathrm{Si}$ e $\mathrm{Al}-6 \% \mathrm{Cu}-4 \% \mathrm{Si}$. A Tabela 2 apresenta um estudo comparativo entre os resultados obtidos neste trabalho e aqueles de artigos publicados anteriormente para ligas à base de alumínio, desenvolvidos nos sistemas de solidificação direcional vertical ascendente e descendente sob condições transientes de extração de calor. Nota-se, que a lei experimental que define o crescimento dos espaçamentos terciários em função da taxa de resfriamento para a solidificação direcional horizontal é dada, conforme mencionado anteriormente, por:

$\lambda_{3}=\mathrm{A}_{2}\left(\mathrm{~T}_{\mathrm{R}}\right)^{-0,55}$

onde o valor da constante $\mathrm{A}_{2}$ depende tanto do tipo e como da composição do soluto, destacando que neste trabalho foi utilizada somente uma composição, verificando-se através da Figura 15 um valor para $A_{2}=52$, muito próximo daquele encontrado por Sá et al [14] e Gomes [17], mostrando que os efeitos impostos pelas convecções térmica e solutal devido, respectivamente, ao gradiente de temperatura provocado pelo superaquecimento e a movimentação de soluto no liquido promovida pela diferença de densidade entre o soluto $(\mathrm{Cu})$ e o solvente $(\mathrm{Al})$, características da solidificação direcional horizontal, praticamente nada influenciam nos espaçamentos dendríticos terciários. Vale destacar, que o cobre possui uma densidade aproximadamente três vezes maior que a do alumínio. Pode-se observar, também, pelos resultados mostrados na Tabela 2, que o silício parece promover um efeito de refinamento na estrutura dendrítica terciária de ligas do sistema $\mathrm{Al}-\mathrm{Si}$ em relação àquela do sistema $\mathrm{Al}-\mathrm{Cu}$ uma vez que a constante $\mathrm{A}_{1}$ obtida para as ligas $\mathrm{Al}-\mathrm{Si}$ apresenta um valor bem menor que aquele determinado para as ligas Al-Cu. 


\subsection{Espaçamentos Dendríticos Terciários $\left(\lambda_{3}\right)$ e Correlação com Variáveis Térmicas de Solidificação $\left(V_{L}\right.$ e $\left.T_{R}\right)$}

A Figura 13 apresenta as microestruturas obtidas experimentalmente para a liga estudada.

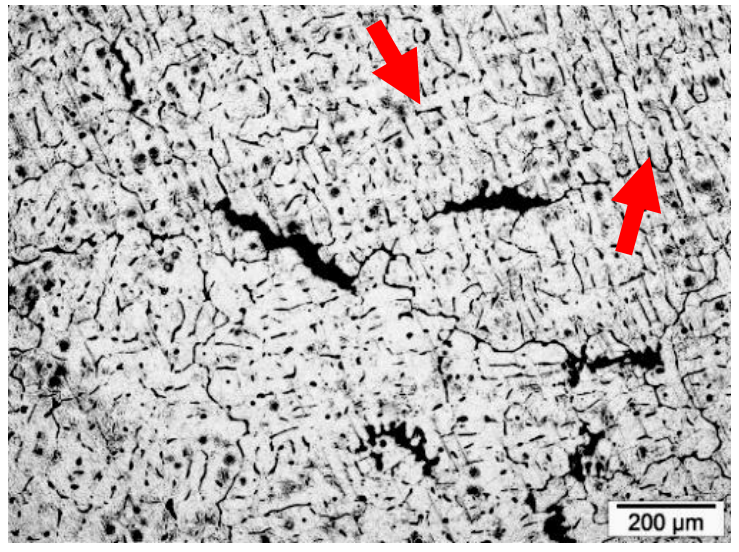

$\mathrm{P}=10 \mathrm{~mm} ; \lambda_{3}=29 \mu \mathrm{m} ; \mathrm{V}_{\mathrm{L}}=0,40 \mathrm{~mm} / \mathrm{s} ; \mathrm{T}_{\mathrm{R}}=1,65^{\circ} \mathrm{C} / \mathrm{s}$

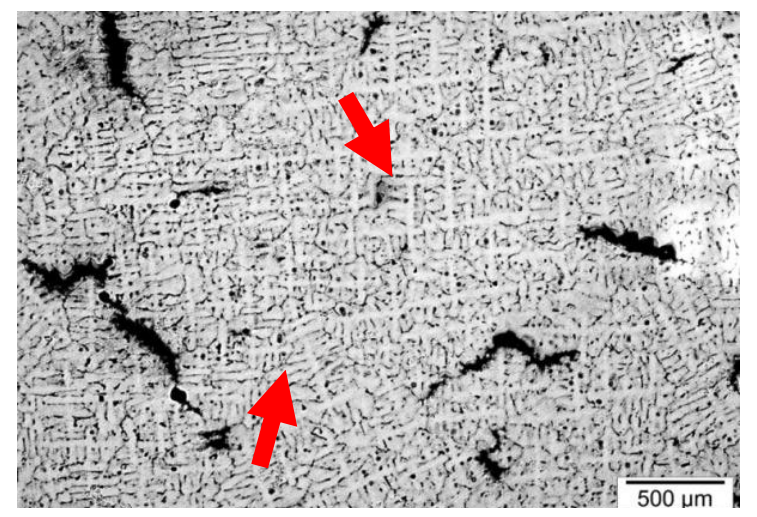

$\mathrm{P}=20 \mathrm{~mm} ; \lambda_{3}=42 \mu \mathrm{m} ; \mathrm{V}_{\mathrm{L}}=0,33 \mathrm{~mm} / \mathrm{s} ; \mathrm{T}_{\mathrm{R}}=1,20^{\circ} \mathrm{C} / \mathrm{s}$

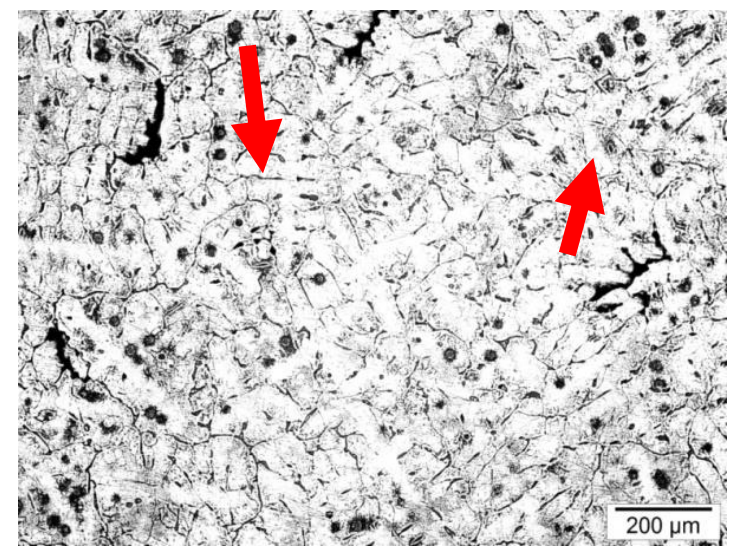

$\mathrm{P}=15 \mathrm{~mm} ; \lambda_{3}=36 \mu \mathrm{m} ; \mathrm{V}_{\mathrm{L}}=0,36 \mathrm{~mm} / \mathrm{s} ; \mathrm{T}_{\mathrm{R}}=1,40{ }^{0} \mathrm{C} / \mathrm{s}$

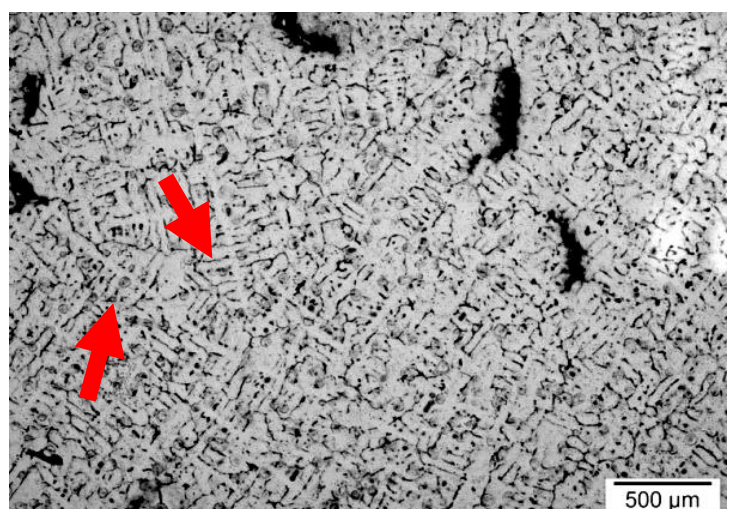

$\mathrm{P}=30 \mathrm{~mm} ; \lambda_{3}=53 \mu \mathrm{m} ; \mathrm{V}_{\mathrm{L}}=0,30 \mathrm{~mm} / \mathrm{s} ; \mathrm{T}_{\mathrm{R}}=0,99^{0} \mathrm{C} / \mathrm{s}$

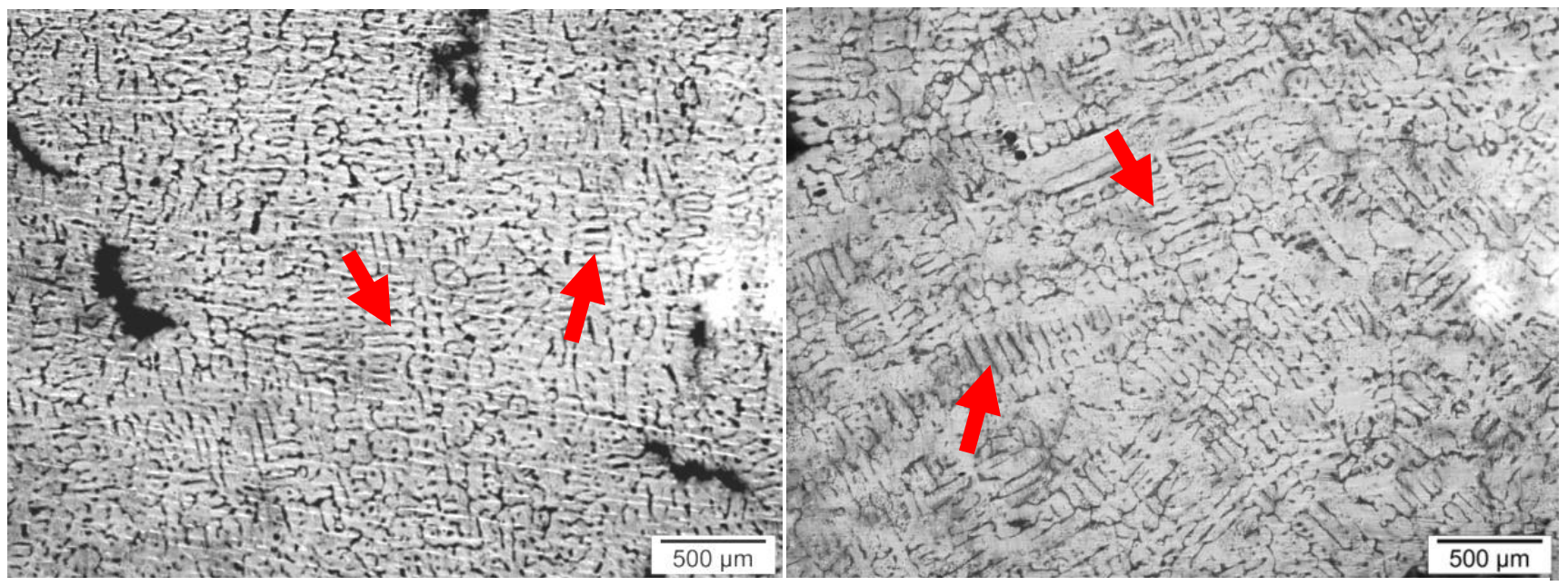

$\mathrm{P}=40 \mathrm{~mm} ; \lambda_{3}=62 \mu \mathrm{m} ; \mathrm{V}_{\mathrm{L}}=0,28 \mathrm{~mm} / \mathrm{s} ; \mathrm{T}_{\mathrm{R}}=0,87{ }^{0} \mathrm{C} / \mathrm{s} \quad \mathrm{P}=50 \mathrm{~mm} ; \lambda_{3}=69 \mu \mathrm{m} ; \mathrm{V}_{\mathrm{L}}=0,26 \mathrm{~mm} / \mathrm{s} ; \mathrm{T}_{\mathrm{R}}=0,79{ }^{0} \mathrm{C} / \mathrm{s}$

Figura 13: Microestrutura brutas de solidificação da liga $\mathrm{Al}-6 \% \mathrm{Cu}$ para diferentes posições em relação à interface metal/molde. As setas representam os braços dendríticos terciários. 
Por outro lado, Sá et al. [14] observando as microestruturas ao longo do corpo de prova para ligas pertencentes aos sistemas $\mathrm{Al}-\mathrm{Cu}$ e $\mathrm{Sn}-\mathrm{Pb}$ durante a solidificação vertical ascendente, constatou que as ramificações dendríticas terciárias parecem iniciar a partir de braços secundários somente quando um certo valor de um fator paramétrico que contempla velocidade, gradiente de temperatura e composição, designado pelos autores por $\delta$, é alcançado. Este fator relaciona a taxa de resfriamento com o teor de soluto da liga, isto é, $\delta=\mathrm{T}_{\mathrm{R}} / \mathrm{C}_{0}$, tendo sido encontrado para ligas $\mathrm{Al}-\mathrm{Cu}$ valores de $\delta<0,4$ que caracterizam as condições de crescimento dos espaçamentos dendríticos terciários. Utilizando-se o fator paramétrico proposto por estes autores, apesar deste trabalho utilizar apenas uma composição de soluto, verifica-se para o caso da liga Al$6 \% \mathrm{Cu}$ valores de $\delta<0,3$ que parecem predizer o surgimento de espaçamentos terciários para a liga em questão quando solidificada nas condições assumidas neste trabalho.

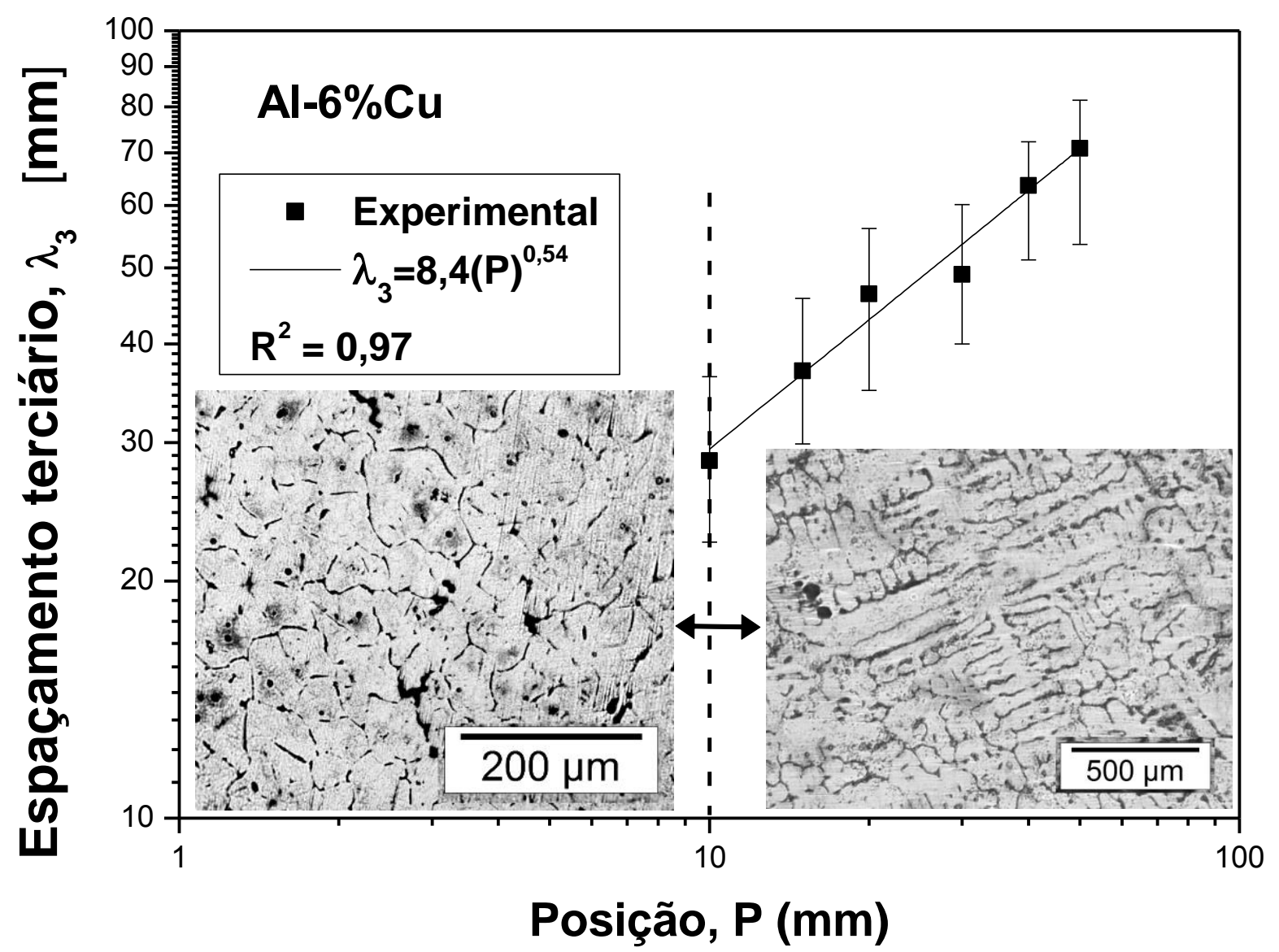

Figura 14: Correlação entre espaçamentos dendríticos terciários com a posição da isoterma liquidus. 


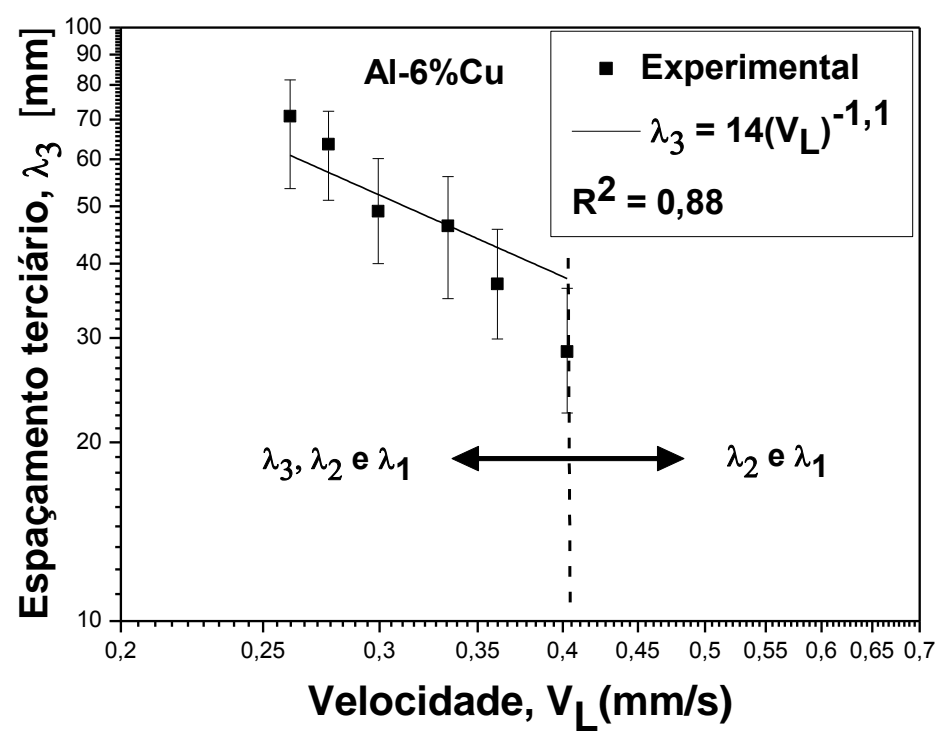

Figura 15: Correlação entre espaçamentos dendríticos terciários com a velocidade de deslocamento da isoterma liquidus.

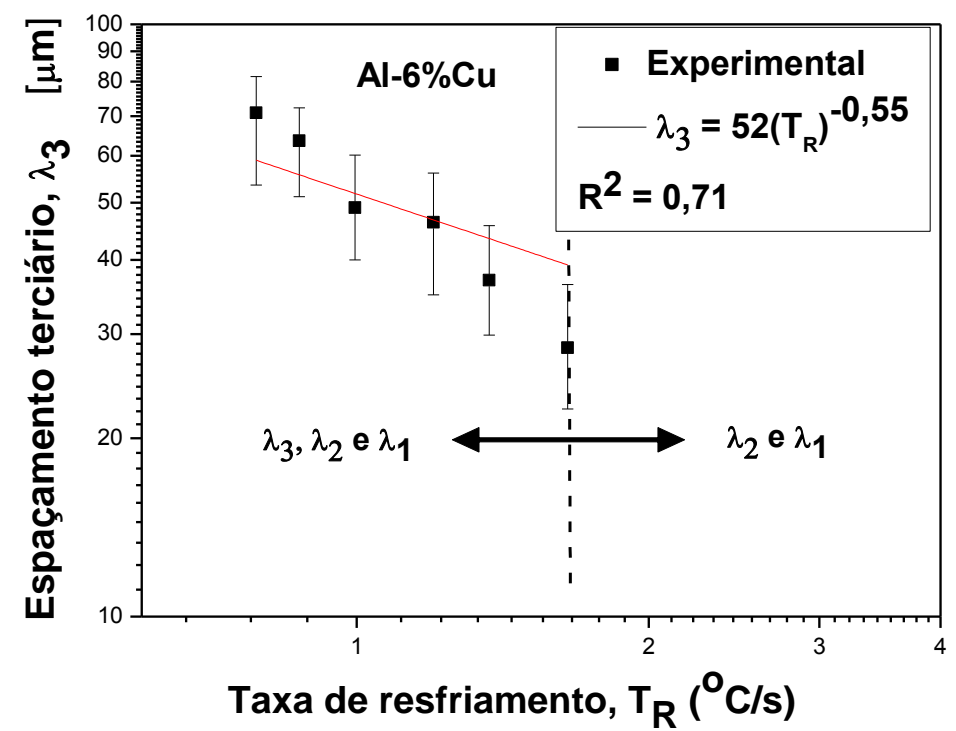

Figura 16: Correlação entre espaçamentos dendríticos terciários com a taxa de resfriamento.

Tabela 2: Leis experimentais para previsão dos espaçamentos dendríticos terciários em ligas dos sistemas $\mathrm{Al}-\mathrm{Cu}, \mathrm{Al}-\mathrm{Si}$ e $\mathrm{Al}-\mathrm{Cu}-\mathrm{Si}$ solidificadas direcionalmente.

\begin{tabular}{cccc}
\hline Autor & Liga & Lei & Equação \\
\hline Sá et al. $[\underline{14}]$ & $\mathrm{Al}-5 \% \mathrm{Cu}$ & \\
Solidificação vertical & $\mathrm{Al}-8 \% \mathrm{Cu}$ & $\lambda_{3}=50\left(\mathrm{~T}_{\mathrm{R}}\right)^{-0,55}$ & $(5)$ \\
ascendente & $\mathrm{Al}-10 \% \mathrm{Cu}$ & & \\
& $\mathrm{Al}-15 \% \mathrm{Cu}$ & \\
\hline
\end{tabular}




\begin{tabular}{|c|c|c|c|}
\hline Rosa et al. [19] & $\mathrm{Al}-5 \% \mathrm{Si}$ & \multirow{3}{*}{$\lambda_{3}=18\left(\mathrm{~T}_{\mathrm{R}}\right)^{-0,55}$} & \multirow{3}{*}{ (6) } \\
\hline \multirow{2}{*}{$\begin{array}{c}\text { Solidificação vertical } \\
\text { ascendente e } \\
\text { descendente }\end{array}$} & $\mathrm{Al}-7 \% \mathrm{Si}$ & & \\
\hline & $\mathrm{Al}-9 \% \mathrm{Si}$ & & \\
\hline \multirow{3}{*}{$\begin{array}{l}\text { Moutinho [16] } \\
\text { Solidificação vertical } \\
\text { ascendente }\end{array}$} & $\mathrm{Al}-6 \% \mathrm{Cu}-1 \% \mathrm{Si}$ & \multirow{3}{*}{$\lambda_{3}=41,2\left(\mathrm{~T}_{\mathrm{R}}\right)^{-0,55}$} & \multirow{3}{*}{ (7) } \\
\hline & & & \\
\hline & $\mathrm{Al}-6 \% \mathrm{Cu}-4 \% \mathrm{Si}$ & & \\
\hline \multirow{3}{*}{$\begin{array}{c}\text { Gomes [17] } \\
\text { Solidificação vertical } \\
\text { ascendente }\end{array}$} & $\mathrm{Al}-3 \% \mathrm{Cu}-5.5 \% \mathrm{Si}$ & \multirow{3}{*}{$\lambda_{3}=50\left(\mathrm{~T}_{\mathrm{R}}\right)^{-0,55}$} & \multirow{3}{*}{ (8) } \\
\hline & \multirow{2}{*}{$\mathrm{Al}-3 \% \mathrm{Cu}-9 \% \mathrm{Si}$} & & \\
\hline & & & \\
\hline Este trabalho & \multirow{2}{*}{$\mathrm{Al}-6 \% \mathrm{Cu}$} & \multirow{2}{*}{$\lambda_{3}=52\left(\mathrm{~T}_{\mathrm{R}}\right)^{-0,55}$} & \multirow[b]{2}{*}{ (9) } \\
\hline Solidificação horizontal & & & \\
\hline
\end{tabular}

\section{CONCLUSÕES}

Os resultados experimentais obtidos e analisados neste trabalho permitem que sejam extraídas as seguintes conclusões:

- Conforme esperado, os valores experimentais de $V_{L}, T_{R}$ e $G_{L}$ diminuem com o avanço da isoterma liquidus, isto é, quanto mais próximo da base refrigerada maiores são esses parâmetros. Os mesmos podem ser representados por equações na forma de potência em função da posição dadas, respectivamente, por $\mathrm{V}_{\mathrm{L}}=0,75(\mathrm{P})^{-0,27}, \mathrm{~T}_{\mathrm{R}}=4,76(\mathrm{P})^{-0,46}$ e $\mathrm{G}_{\mathrm{L}}=7,15(\mathrm{P})^{-0,2}$.

- Os espaçamentos dendríticos terciários aumentam progressivamente da interface metal/molde para o interior do lingote uma vez que a ação do fluido de refrigeração impõe valores de velocidades, taxas de resfriamento e gradientes térmicos bastante elevados próximo à base refrigerada sendo que estes diminuem gradativamente durante a solidificação em função do aumento da resistência térmica promovida pela formação do metal sólido.

- Para a liga Al-6\%Cu, solidificada nas condições impostas neste trabalho, a evolução dos espaçamentos dendríticos terciários pode ser representada por uma lei experimental de crescimento dada pela forma geral $\lambda_{3}=\mathrm{A}_{2}\left(\mathrm{~T}_{\mathrm{R}}\right)^{-0,55}$, onde $\lambda_{3}[\mu \mathrm{m}], \mathrm{T}_{\mathrm{R}}[\mathrm{K} / \mathrm{s}]$ e $\mathrm{A}_{2}$ é uma constante que depende do tipo de soluto. No caso investigado, o valor obtido para $A_{2}$ é igual a 52 muito próximo daquele encontrado para ligas Al-Cu solidificadas na direção vertical ascendente.

- Com base no fator paramétrico proposto por Sá et al. [14], observou-se neste trabalho que valores de $\delta<0,3$ parecem predizer o surgimento de espaçamentos dendríticos terciários na liga $\mathrm{Al}-6 \% \mathrm{Cu}$. No entanto, visando melhor avaliar a influência de fatores térmicos e da composição no surgimento de ramificações dendríticas terciárias durante a solidificação direcional horizontal de ligas do sistema $\mathrm{Al}-\mathrm{Cu}$, ainda são necessários estudos mais aprofundados capazes de investigar a real influência da variação do teor de soluto no surgimento desses espaçamentos dendríticos.

- Os resultados encontrados indicam que a convecção termossolutal parece não influenciar os valores dos espaçamentos dendríticos terciários da liga estudada quando solidificada segundo as condições assumidas neste estudo.

- Finalmente, uma análise comparativa entre os resultados obtidos neste trabalho e aqueles existentes na literatura mostra que o silício parece promover um efeito de refinamento na estrutura dendrítica terciária de ligas do sistema Al-Si em relação àquela observada em ligas do sistema Al$\mathrm{Cu}$ uma vez que a constante $\mathrm{A}_{1}$ obtida para as ligas $\mathrm{Al}-\mathrm{Si}$ apresenta um valor bem menor que aquele determinado para as ligas $\mathrm{Al}-\mathrm{Cu}$. 


\section{AGRADECIMENTOS}

Os autores agradecem ao Conselho Nacional de Desenvolvimento Científico e Tecnológico (CNPq) - Brasil, à Fundação da Amazônia Paraense (FAP) e ao Instituto Federal de Educação, Ciência e Tecnologia do Pará (IFPA) pelo apoio financeiro e na concessão de bolsas de Iniciação Científica e de Desenvolvimento Tecnológico para os alunos do IFPA.

\section{BIBLIOGRAFIA}

[1] GARCIA, A., Solidificação: Fundamentos e Aplicações, 2 ed., Campinas, Editora da Unicamp, 2007.

[2] HUNT, J.D., "Steady State Columnar and Equiaxed Growth of Dendrites and Eutetic", Materials Science and Engineering, v.65, pp. 75-83, Jul. 1984.

[3] KURZ, W., FISHER, J., "Dendrite Growth at the Limit of Stability: Tip Radius and Spacing", Acta Metallurgica, v.29, pp. 11-20, Jan. 1981.

[4] BOUCHARD, D., KIRKALDY, J.S., "Scaling of Intragranular Dendritic Microstructure in Ingot Solidification” Metallurgical Materials Transactions B, v.27B, pp. 101-113, Feb. 1996.

[5] HUNT, J.D., LU, S.Z.,"Numerical Modeling of Cellular Array Growth: Spacing and Structure Predictions”, Metallurgical and Materials Transactions A, v.27A, pp. 611-623, Mar. 1996.

[6] GÜNDÜZ, M., ÇADIRLI, E., "Directional Solidification of Aluminium-Copper Alloys", Materials Science and Engineering A, v.327, pp. 167-185, Apr. 2002.

[7] ROCHA, O.L., SIQUEIRA, C.A., GARCIA, A., “Cellular/Dendritic Transition During Unsteady-State Unidirectional Solidification of Sn-Pb Alloys", Materials Science and Engineering A, v.347, pp. 59-69, Apr. 2003.

[8] ROCHA, O.L., SIQUEIRA, C.A., GARCIA, A., "Heat Flow Parameters Affecting Dendrite Spacings During Unsteady-State Solidification of $\mathrm{Sn}-\mathrm{Pb}$ and $\mathrm{Al}-\mathrm{Cu}$ Alloys", Metallurgical and Materials Transactions A, v.34A, pp. 995-1006, Apr. 2003.

[9] CANTÉ, M.V., CRUZ, K.S., SPINELLI, J.E., et al., "Experimental Analysis of the Columnar-toEquiaxed Transition in Directionally Solidified Al-Ni and Al-Sn Alloys", Materials Letters, v.61, pp. 2135 2138, May. 2007.

[10] CRUZ, K.S., MEZA, E.S., FERNANDES, F.A.P., et al., "Dendritic Arm Spacing Affecting Mechanical Properties and Wear Behavior of Al-Sn and Al-Si Alloys Directionally Solidified Under Unsteady-State Conditions", Metallurgical and Materials Transactions, v.41, pp. 972-984, Apr. 2010.

[11] SPINELLI, J.E., FERREIRA, I.L., GARCIA, A., "Influence of Melt Convection on the Columnar to Equiaxed Transition and Microstructure of Downward Unsteady-State Directionally Solidified $\mathrm{Sn}-\mathrm{Pb}$ Alloys", Journal of Alloys and Compounds, v.384, pp. 217-226, Dec. 2004.

[12] ROSA, D.M., SPINELLI, J.E., FERREIRA, I.L., et al., "Cellular/Dendritic Transition and Microstructure Evolution During Transient Directional Solidification of $\mathrm{Pb}-\mathrm{Sb}$ Alloys", Metallurgical and Materials Transactions, v.39, pp. 161-2174, Sep. 2008.

[13] OKAMOTO, T., KISHITAKE, K., "Dendritic Structure in Unidirectionally Solidified Aluminum, Tin, and Zinc Based Binary Alloys", Journal of Crystal Growth, v.29, pp. 137-146, Jun. 1975.

[14] SÁ, F.A., ROCHA, O.L., SIQUEIRA, C.A., et al., "The Effect of Solidification Variables on Tertiary Dendrite Arm Spacing in Unsteady-State Directional Solidification of $\mathrm{Sn}-\mathrm{Pb}$ and Al-Cu Alloys", Materials Science and Engineering A, v.373, pp. 131-138, May. 2004.

[15] ORDORICA, M.A.S., RAPPAZ, M., “Twinned Dendrite Growth in Binary Aluminum Alloys", Acta Materialia, v.56, pp. 5708-5718, Nov. 2008.

[16] MOUTINHO, D.J.C., Análise da Evolução Microestrutural e da Formação de Macrossegregação e Microporosidade na Solidificação Unidirecional Transitória de Ligas Ternárias Al-Cu-Si, Tese de D.Sc., UNICAMP, Campinas, SP, Brasil, 2012.

[17] GOMES, L.G., Microestrutura Dendrítica, Macrossegregação e Microporosidade na Solidificação de Ligas Ternárias Al-Si-Cu, Tese de D.Sc., UNICAMP, Campinas, SP, Brasil, 2012. 
[18] SPINELLI, J.E., FERREIRA, I.L., GARCIA, A., "Evaluation of Heat Transfer Coefficients During Upward and Downward Transient Directional Solidification of Al-Si Alloys", Structural and Multidisciplinary Optimization, v.31, pp. 241-248, Jan. 2006.

[19] ROSA, D.M., SPINELLI, J.E., GARCIA, A., “Tertiary Dendrite Arm Spacing During Downward Transient Solidification of Al-Cu and Al-Si Alloys”, Materials Letters, v.60, pp. 1871-1874, Jul. 2006.

[20] SILVA, J.N., MOUTINHO, D.J., MOREIRA, A.L. et al. "The Columnar to Equiaxed Transition During the Horizontal Directional Solidification of Sn-Pb Alloys", Journal of Alloys and Compounds, v.478, pp. 358-366, Jun. 2009.

[21] SILVA, J.N., MOUTINHO, D.J., MOREIRA, A.L. et al. "Determination of Heat Transfer Coefficients at Metal-Mold Interface During Horizontal Unsteady-State Directional Solidification of Sn-Pb Alloys", Materials Chemistry and Physics, v.130, pp. 179-185, Oct. 2011.

[22] GURGEL, R.N., "Secondary and Tertiary Dendrite Arm Spacing Relationships in Directionally Solidified Al-Si Alloys”, Journal of Materials Science, v.28, pp. 677-683, Feb. 1993.

[23] BOEIRA, A.P., FERREIRA, I.L., GARCIA, A., "Modeling of Macrosegregation and Microporosity Formation During Transient Directional Solidification of Aluminum Alloys", Materials Science and Engineering A, v.435, pp. 150-157, Nov. 2006.

[24] McCARTNEY, D.G., HUNT, J.D., "Measurements of Cells and Primary Dendrite Arm Spacing in Directionally Solidified Aluminium Alloys”, Acta Metallurgica, v.29, pp. 1851-1863, Nov. 1981. 